\title{
A NiFe Alloy Reduced on Graphene Oxide for Electrochemical Nonenzymatic Glucose Sensing
}

\author{
Zhe-Peng Deng ${ }^{1,2}$, Yu Sun ${ }^{3}$, Yong-Cheng Wang ${ }^{1, *}$ and Jian-De Gao ${ }^{4}$ \\ 1 College of Chemistry and Chemical Engineering, Northwest Normal University, Lanzhou 730070, China; \\ dengzp516@163.com \\ 2 Gansu Computing Center, Lanzhou 730030, China \\ 3 Experiment Center of Northwest University for Nationalities, Lanzhou 730030, China; sunyu794@163.com \\ 4 College of Pharmacy, Gansu University of Chinese Medicine, Lanzhou 730000, China; 13919124704@163.com \\ * Correspondence: wangyc@nwnu.edu.cn; Tel.: +86-931-7971989
}

Received: 17 October 2018; Accepted: 13 November 2018; Published: 15 November 2018

check for updates

\begin{abstract}
A NiFe alloy nanoparticle/graphene oxide hybrid (NiFe/GO) was prepared for electrochemical glucose sensing. The as-prepared NiFe/GO hybrid was characterized by transmission electron microscopy (TEM) and X-ray diffraction (XRD). The results indicated that NiFe alloy nanoparticles can be successfully deposited on GO. The electrochemical glucose sensing performance of the as-prepared NiFe/GO hybrid was studied by cyclic voltammetry and amperometric measurement. Results showed that the NiFe/GO-modified glassy carbon electrode had sensitivity of $173 \mu \mathrm{A} \mathrm{mM}^{-1} \mathrm{~cm}^{-2}$ for glucose sensing with a linear range up to $5 \mathrm{mM}$, which is superior to that of commonly used Ni nanoparticles. Furthermore, high selectivity for glucose detection could be achieved by the NiFe/GO hybrid. All the results demonstrated that the NiFe/GO hybrid has promise for application in electrochemical glucose sensing.
\end{abstract}

Keywords: NiFe alloy; graphene oxide; glucose; nonenzymatic sensor

\section{Introduction}

Glucose sensing is important in many fields, such as medical diagnostics and the food industry [1]. The earliest glucose sensing was reported by Clark and Lyons in 1962, using a biological enzyme [2]. Since then, biological enzymes such as glucose oxidase and glucose dehydrogenase have been widely used for glucose sensing. However, biological enzymes are susceptible to external conditions such as temperature, humidity, and $\mathrm{pH}$, among others, which lead to the instability of the biological enzymes [3-5]. The expensive price and complicated mobilizing methods of biological enzymes also restrict their application [6]. Therefore, to address these problems, the research focus has been transferred to the development of electrochemical nonenzymatic glucose sensors.

Due to its high stability and sensitivity, nonenzymatic electrochemical technology is a good choice for glucose sensing [7]. Various nanoparticles have been reported for constructing electrochemical nonenzymatic biosensors, such as noble metal Pt nanoparticles (Pt NPs) [3,8,9], Au NPs [10,11], and Pd NPs $[12,13]$. However, the expensive price of these noble metals restricts their practical application. Furthermore, noble metal-constructed electrochemical glucose sensors are usually poisoned by chloride ions present in the body's blood [14]. In order to exploit cheap electrochemical nonenzymatic glucose biosensors, considerable attention has been focusing on non-noble metal materials, such as Ni NPs [15-17], $\mathrm{Co}(\mathrm{OH})_{2}$ nanotubes [18], and $\mathrm{Cu}$ NPs [19,20]. Recent studies reveal that bimetallic materials [21], especially bimetal alloys, exhibit better catalytic performance than that of monometallic counterparts [22]. Xu et al. and Chen et al. both found that a Pt-Ni alloy exhibited enhanced sensitivity 
for glucose sensing [23,24]. Besides, a PtRu alloy [25], PtAu alloy [26], PtCo alloy [27], CoCu alloy [28], and NiCo alloy [29] have been used in glucose sensing.

A support material is also important in electrochemical glucose sensors [30]. Carbon-based materials (especially carbon nanotubes and graphene) have been extensively used to load the electrochemical catalyst due to their excellent conductivity, such as in loading cupric oxide [31] or growing copper nanoparticles [32] on carbon nanotubes (CNTs) for electrochemical glucose sensing. Graphene and its oxide (graphene oxide, GO) have triggered researchers' interest since 2004 because of their good electrical conductivity and large specific surface area. Due to these exceptional properties, graphene and GO have often been chosen as the supporting material in electrochemistry [33]. GO loaded with NiS [34], NiCo alloy [29], and CuS NPs [35] have been applied for electrochemical glucose sensing.

Based on the above considerations, we tried to study the alloying of commonly used Ni NPs in the scope of glucose detection with Feon GO, because the NiFe alloy shows high electrochemical performance in various processes [36-39]. To the best of our knowledge, the NiFe alloy nanoparticle/graphene oxide hybrid (NiFe/GO) has never been reported for electrochemical glucose sensing. The NiFe/GO hybrid reveals better electrocatalytic performance towards glucose oxidation than the commonly used Ni NPs. The high performance of NiFe alloy nanoparticles and the superior conductivity of GO endow the NiFe/GO biosensor with the capacity to achieve the electrochemical sensing of glucose in a wide concentration range.

\section{Materials and Methods}

\subsection{Chemicals and Reagents}

All reagents used in experiments were of analytical grade. Graphite powder was purchased from Alfa Aesar (Shanghai, China). Nickel sulfate hexahydrate, iron sulfate heptahydrate, hydrazine hydrate $(80 \mathrm{wt} \%)$, and glucose were procured from Sinopharm Chemical Reagent Co., Ltd. (Shanghai, China). Ascorbic acid (AA), uric acid (UA), and dopamine (DA) were purchased from Acros (Shanghai, China). Deionized water $(18.2 \mathrm{M} \Omega \cdot \mathrm{cm})$ was used in all experiments.

\subsection{Preparation of $G O$}

GO was prepared by a modified Hummers' method [40]. Two grams of graphite and $1 \mathrm{~g} \mathrm{NaNO}_{3}$ were mixed with $50 \mathrm{~mL} \mathrm{H}_{2} \mathrm{SO}_{4}(95 \%)$ in a $250 \mathrm{~mL}$ flask within an ice bath to keep a low temperature (note that the ice bath is important and necessary). Then, $6 \mathrm{~g} \mathrm{KMnO}_{4}$ was added slowly into the above suspension with vigorous stirring. In this adding process, the reaction temperature was kept below $20{ }^{\circ} \mathrm{C}$. After that, the mixture was stirred at room temperature overnight. Subsequently, $60 \mathrm{~mL} \mathrm{H}_{2} \mathrm{O}$ was added slowly with vigorous agitation. The reaction temperature was increased rapidly up to $95^{\circ} \mathrm{C}$, and the color of the suspension changed to yellow. Then, $10 \mathrm{~mL}$ of $30 \% \mathrm{H}_{2} \mathrm{O}_{2}$ was added to the mixture. Finally, the obtained product was washed by rinsing with $5 \% \mathrm{HCl}$ and then deionized water for several times until the $\mathrm{pH}$ of filtrate reached 7 . After drying in a vacuum dryer, GO as a gray powderwas obtained.

\subsection{Preparation of the NiFe/GO Composite}

For the preparation of the $\mathrm{NiFe} / \mathrm{GO}$ composite (for example, the ratio of $\mathrm{Ni}$ to $\mathrm{Fe}$ is 1:1, denoted as $\mathrm{NiFe} / \mathrm{GO}), 0.1 \mathrm{~g}$ of the as-prepared GO, $278.1 \mathrm{mg} \mathrm{FeSO}{ }_{4} \cdot 7 \mathrm{H}_{2} \mathrm{O}(1 \mathrm{mmol})$, and $262.9 \mathrm{mg} \mathrm{NiSO} \cdot 6 \mathrm{H}_{2} \mathrm{O}$ $(1 \mathrm{mmol})$ were added to $10 \mathrm{~mL}$ deionized water. The mixture was sonicated for $30 \mathrm{~min}$ to get an evenly dispersed solution. Then, $15 \mathrm{~mL}$ hydrazine hydrate was dropped slowly into the above solution followed by refluxing at $100{ }^{\circ} \mathrm{C}$ for $3 \mathrm{~h}$ under $\mathrm{N}_{2}$ atmosphere. After reaction, the obtained NiFe/GO composite was washed using deionized water for several times. Finally, the washed NiFe/GO composite was dried in a vacuum for further use. Other composites (different Ni-to-Fe mass ratios, 
such as $\mathrm{Ni}_{1} \mathrm{Fe}_{4} / \mathrm{GO}, \mathrm{Ni}_{4} \mathrm{Fe}_{1} / \mathrm{GO}, \mathrm{Ni} / \mathrm{GO}$, and $\mathrm{Fe} / \mathrm{GO}$ ) were prepared by adjusting the ratio of $\mathrm{Ni}$ and Fe. NiFe alloy NPs were also prepared for comparison using the same method without adding GO.

\subsection{Preparation of the NiFe/GO Hybrid Modified Electrode}

Five milligrams of NiFe/GO hybrid was dispersed in $1 \mathrm{~mL}$ of solution containing $0.5 \mathrm{~mL}$ ethyl alcohol and $0.5 \mathrm{~mL}$ deionized water. The above solution was sonicated for 30 min to get an evenly dispersed mixture. After sonicating, a certain amount of the mixture was dropped onto a bare glassy carbon electrode (GCE), followed by adding $2 \mu \mathrm{L}$ Nafion solution (0.5\%) to entrap the NiFe/GO. The prepared electrode was denoted as NiFe/GO/GCE. For comparison, Ni/GO/GCE, Fe/GO/GCE, and NiFe/GCE were fabricated similarly.

\subsection{Apparatus and Measurements}

The morphologies of the NiFe/GO composite were collected with a $\mathrm{G}^{2} \mathrm{~F}^{30}$ electron microscope (Tecnai, Hillsboro, OR, USA). XRD data were conducted on a D/max-2400 diffractometer (Rigaku, Beijing, China ) operating at a voltage of $40 \mathrm{kV}$ and a current of $40 \mathrm{~mA}$, using Cu-K radiation as the X-ray source. Electrochemical characterization was performed on a CHI 660C electrochemical workstation (CH Instruments Ins, Shanghai, China) with the modified GCE as the working electrode, $\mathrm{Pt}$ wire as the counter electrode, and $\mathrm{Ag} / \mathrm{AgCl}(3 \mathrm{M} \mathrm{KCl})$ as the reference electrode. All voltages used in the manuscript refer to the $\mathrm{Ag} / \mathrm{AgCl}(3 \mathrm{M} \mathrm{KCl})$ electrode.

\section{Results and Discussion}

\subsection{Structural Characterization}

The TEM image of the NiFe/GO composite is displayed in Figure 1. As shown in Figure 1a, NiFe alloy with diameter of about $100 \mathrm{~nm}$ are loaded on the GO. Figure $1 \mathrm{~b}-\mathrm{d}$ shows the element mapping of the NiFe alloy. It can be seen clearly that the $\mathrm{Ni}$ and Fe elements are evenly distributed in the $\mathrm{NiFe}$ alloy. This proves the successful preparation of the NiFe alloy. Figure 2 shows the XRD pattern of $\mathrm{NiFe} / \mathrm{GO}$ to further investigate the crystalline structure. The diffraction patterns located at $44.5^{\circ}, 51.9^{\circ}$, and $76.4^{\circ}$ can be ascribed to the diffraction of the (111), (200), and (220) crystal planes of the NiFe alloy, respectively [41]. No peaks of GO could be found due to its small amount.

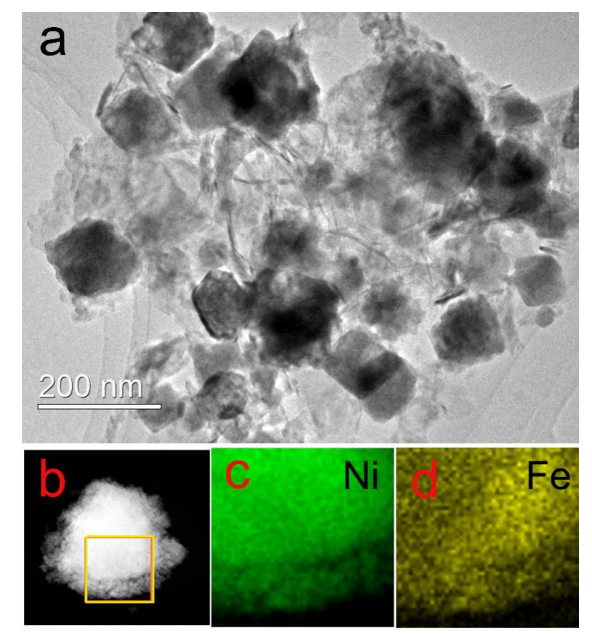

Figure 1. (a) TEM image of the NiFe/GO composite and (b-d) element mapping of the NiFe alloy. 


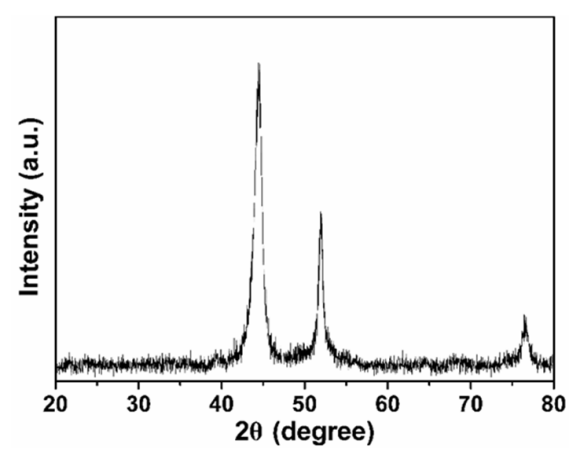

Figure 2. XRD pattern of the NiFe/GO composite.

\subsection{Electrochemical Measurements}

Figure 3 shows the typical cyclic voltammograms of the as-prepared GCE, GO/GCE, Fe/GO/GCE, $\mathrm{Ni} / \mathrm{GO} / \mathrm{GCE}$, and $\mathrm{NiFe} / \mathrm{GO} / \mathrm{GCE}$ in $0.1 \mathrm{M} \mathrm{NaOH}$ solution in the presence of $1.0 \mathrm{mM}$ glucose. It can be seen from Figure 3 that GCE, GO/GCE, and Fe/GO/GCE show very small current in the whole voltage range. Oxidation peaks between 0.50 to $0.55 \mathrm{~V}$ can be observed for Ni/GO/GCE and $\mathrm{NiFe} / \mathrm{GO} / \mathrm{GCE}$, which can be ascribed to the oxidation of $\mathrm{Ni}^{2+}$ to $\mathrm{Ni}^{3+}$. The $\mathrm{Ni}^{3+}$ accounts for the oxidation of glucose [15]. When Fe was added to Ni to form the NiFe alloy, the current clearly increased. This indicates that the NiFe alloy has higher performance for electrochemical glucose detection.

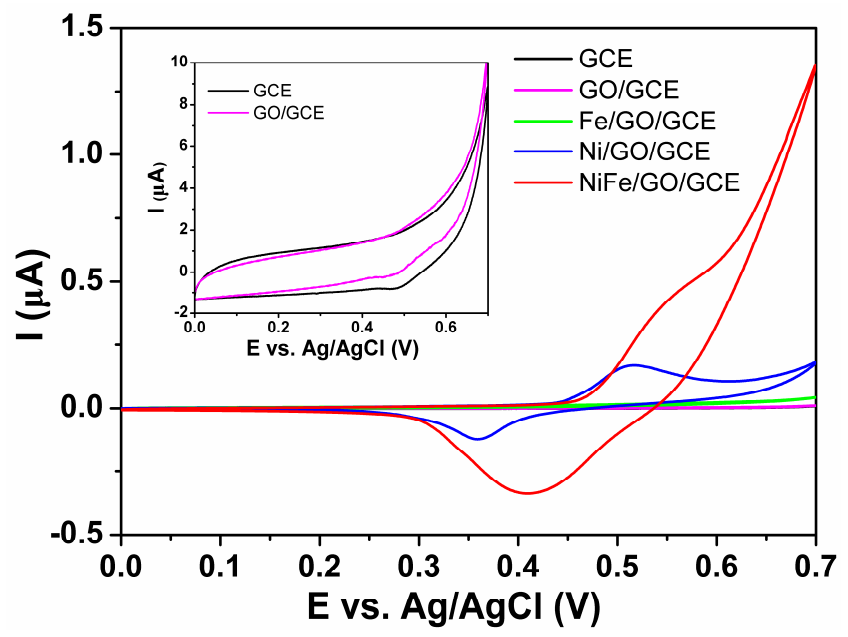

Figure 3. Cyclic voltammograms (CVs) of GCE, GO/GCE, Fe/GO/GCE, Ni/GO/GCE, and $\mathrm{NiFe} / \mathrm{GO} / \mathrm{GCE}$ in $0.1 \mathrm{M} \mathrm{NaOH}$ solution in the presence of $1.0 \mathrm{mM}$ glucose at a scan rate of $10 \mathrm{mV} / \mathrm{s}$. Inset: CVs of GCE and GO/GCE.

To illustrate the effect of GO, the performance of NiFe/GCE and NiFe/GO/GCE were investigated. As shown in Figure 4, NiFe/GCE has only negligible current and the redox peaks can be seen in the inset figure. $\mathrm{NiFe/GO/GCE} \mathrm{shows} \mathrm{much} \mathrm{larger} \mathrm{current} \mathrm{than} \mathrm{that} \mathrm{of} \mathrm{NiFe/GCE,} \mathrm{indicating} \mathrm{GO} \mathrm{is}$ important in the composite electrode. The GO not only acts as the support to protect the NiFe alloy from aggregation, but also plays an important role for electronic transmission. 


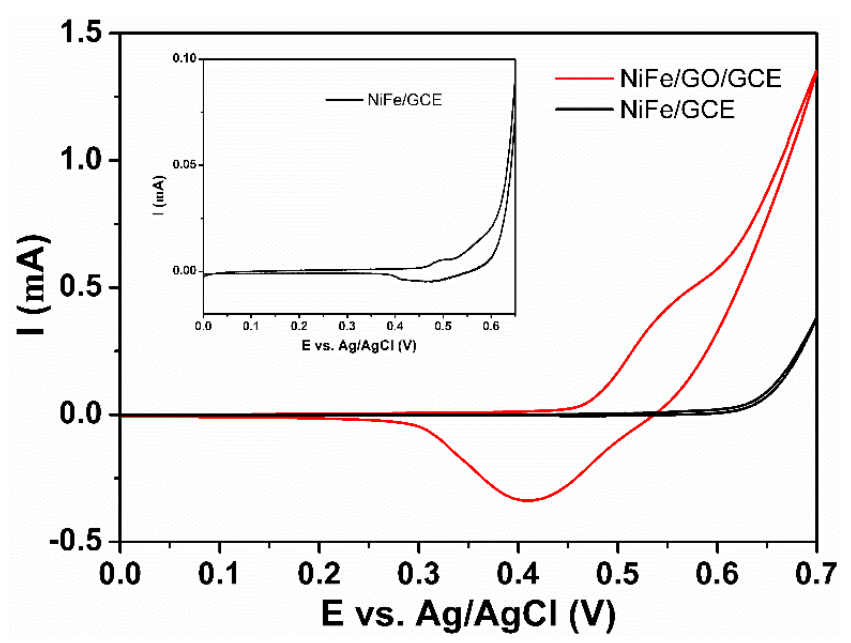

Figure 4. $\mathrm{CVs}$ of $\mathrm{NiFe} / \mathrm{GCE}$ and $\mathrm{NiFe} / \mathrm{GO} / \mathrm{GCE}$ in $0.1 \mathrm{M} \mathrm{NaOH}$ solution in the presence of $1.0 \mathrm{mM}$ glucose at a scan rate of $10 \mathrm{mV} / \mathrm{s}$. Inset: $\mathrm{CV}$ of $\mathrm{NiFe} / \mathrm{GCE}$.

Furthermore, the effect of the ratio between the $\mathrm{Ni}$ and Fe elements were investigated. As shown in Figure 5, $\mathrm{Ni}_{1} \mathrm{Fe}_{4} / \mathrm{GO} / \mathrm{GCE}$ shows the smallest current. With the increase of $\mathrm{Ni}$ amount, $\mathrm{NiFe} / \mathrm{GO} / \mathrm{GCE}$ shows the biggest current. Conversely, a greater amount of $\mathrm{Ni}$ decreases the current for $\mathrm{Ni}_{4} \mathrm{Fe}_{1} / \mathrm{GO} / \mathrm{GCE}$. So, NiFe/GO/GCE was used for further research.

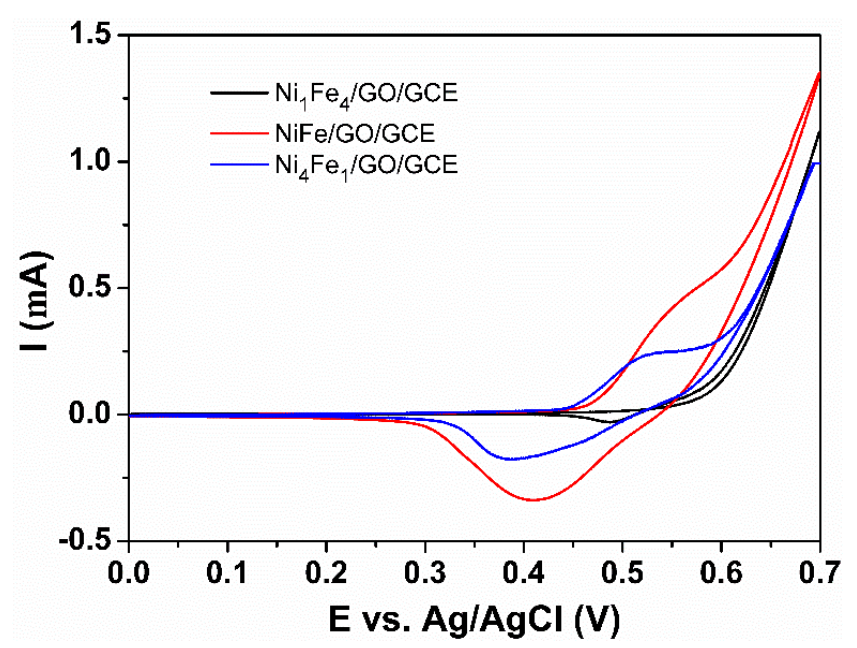

Figure 5. $\mathrm{CVs}$ of $\mathrm{Ni}_{1} \mathrm{Fe}_{4} / \mathrm{GO} / \mathrm{GCE}$, $\mathrm{NiFe} / \mathrm{GO} / \mathrm{GCE}$, and $\mathrm{Ni}_{4} \mathrm{Fe}_{1} / \mathrm{GO} / \mathrm{GCE}$ in $0.1 \mathrm{M} \mathrm{NaOH}$ solution in the presence of $1.0 \mathrm{mM}$ glucose at a scan rate of $10 \mathrm{mV} / \mathrm{s}$.

In order to improve the electrocatalytic performance of NiFe/GO/GCE, the loading amount of NiFe/GO was studied. Figure 6 shows the cyclic voltammogram (CV) curves of NiFe/GO/GCE with different amounts of $\mathrm{NiFe} / \mathrm{GO}$ loaded onto the GCE. It can be seen that the current increases gradually from the loading amount of 30 to $75 \mu \mathrm{g}$ NiFe/GO. When the loading amount exceeds $60 \mu \mathrm{g}$, the current decreases. So, $60 \mu \mathrm{g}$ is the optimum loading amount and is used in the later experiments. This phenomenon can be explained by the change of catalytic sites. At first, increasing the loading amount of the NiFe alloy increased the number of catalytic sites. However, an excessive loading amount limited the mass transfer process, leading to the decrease of current [19].

Cyclic voltammetric measurements were performed at increased scan rates to better understand the electrocatalytic properties of the $\mathrm{NiFe} / \mathrm{GO} / \mathrm{GCE}$ electrode for glucose oxidation. As demonstrated in Figure $7 \mathrm{a}$, cathodic peak currents of $\mathrm{NiFe} / \mathrm{GO} / \mathrm{GCE}$ increased with the increasing scan rate. Figure $7 \mathrm{~b}$ illustrates the relationship between the cathodic peak current and scan rate. It can be 
seen that the cathodic peak currents increase linearly with the used scan rates. This result manifested that the rate-determining step was surface reaction control rather than diffusion control, which is favorable for quantitative analysis.

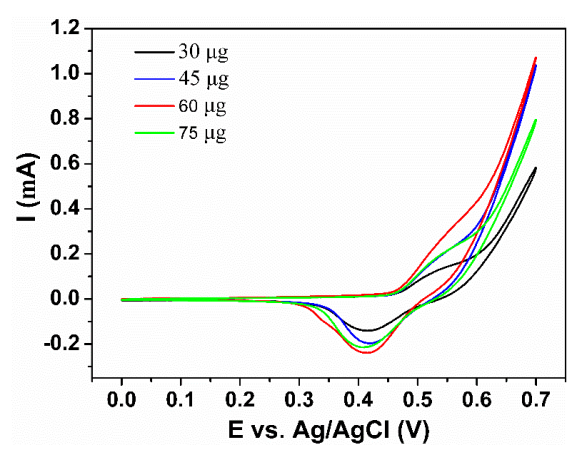

Figure 6. The effect of modification amount on the performance of the electrode.
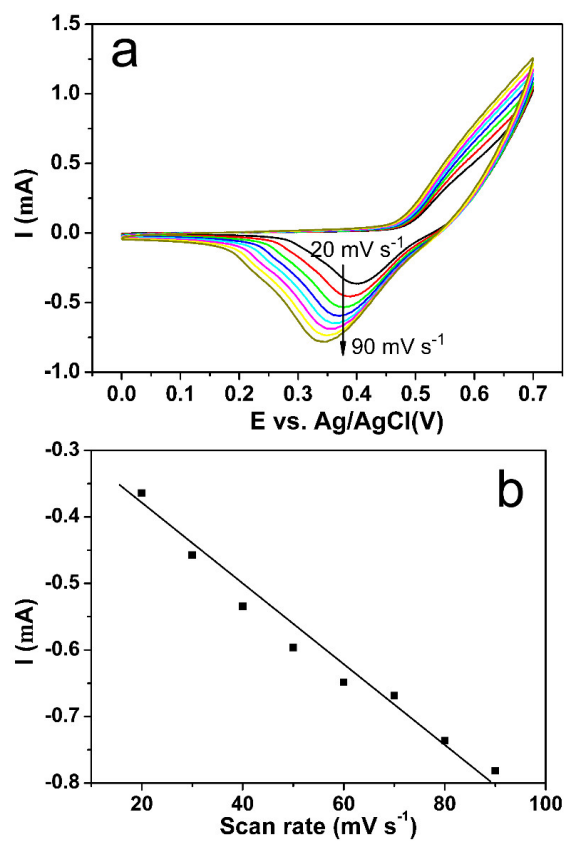

Figure 7. (a) Cyclic voltammograms of NiFe/GO/GCE at different scan rates from 20 to $90 \mathrm{mV} / \mathrm{s}$ in $0.1 \mathrm{M} \mathrm{NaOH}$ with $1.0 \mathrm{mM}$ glucose. (b) Plot of cathode current vs the scan rate.

\subsection{Amperometric Response Towards Glucose Sensing}

Amperometric measurement was carried out to show the current response of the NiFe/GO/GCE electrode towards the continuous addition of various concentrations of glucose, which was carried out in vigorously stirred electrolyte. As shown in Figure 8a, the NiFe/GO/GCE electrode consistently generates a fast current response upon the addition of glucose with concentration from 50 to $400 \mu \mathrm{M}$. According to the amperometric current, the corresponding calibration curve was plotted in Figure $8 \mathrm{~b}$. It can be seen that the NiFe/GO/GCE sensor showed a wide linear sensing range, from 0.05 to $5 \mathrm{mM}$ $(\mathrm{R} 2=0.9994)$, and a sensitivity of $173 \mu \mathrm{A} \mathrm{mM} \mathrm{mM}^{-1} \mathrm{~cm}^{-2}$. The limit of quantitation (LOQ) is $0.05 \mathrm{mM}$, while the limit of detection (LOD) is $9 \mu \mathrm{M}$ at a signal/noise ratio of 3. At low concentrations, as shown in the inset in Figure 8b, the NiFe/GO/GCE sensor also showed a sensitivity of $148 \mu \mathrm{A} \mathrm{mM} \mathrm{m}^{-1} \mathrm{~cm}^{-2}$, which was close to that at high concentrations. As shown in Table 1, the performance of our sensor was compared with the previously reported sensors based on Ni materials. Our sensor is comparable to the previously reported sensors. The high sensitivity can be ascribed to the high electrocatalytic activity of the NiFe alloy and the excellent electronic transmission performance of GO. 

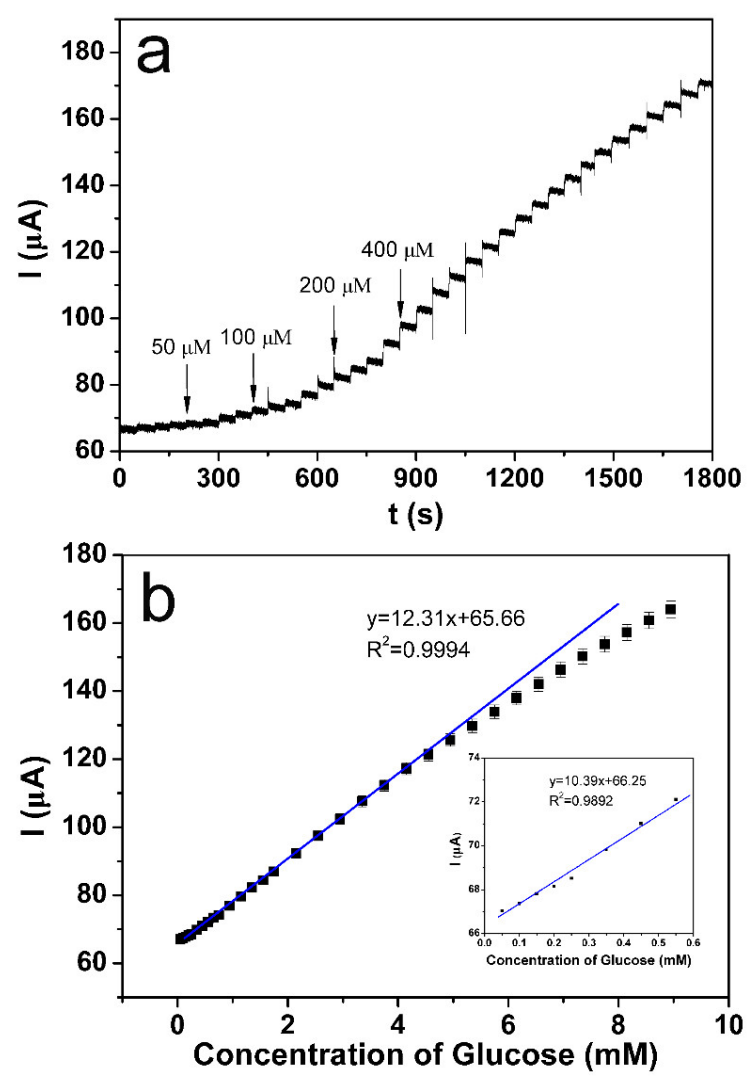

Figure 8. (a) Amperometric currents measured with the continuous addition of glucose with concentration from 50 to $400 \mu \mathrm{M}$ at $0.55 \mathrm{~V}$ for NiFe/GO/GCE, and (b) the corresponding calibration curve. Inset: calibration curve at low concentrations.

Table 1. Comparison of our sensor to other Ni-based sensors.

\begin{tabular}{cccc}
\hline Materials & $\begin{array}{c}\text { Sensitivity } \\
\left(\boldsymbol{\mu} \mathbf{~ m M}^{-\mathbf{1}} \mathbf{~ m}^{-\mathbf{2}} \mathbf{)}\right.\end{array}$ & Linear Range & Reference \\
\hline $\mathrm{Pd}-\mathrm{Ni}$ /Si nanowires & 190.7 & $0-20 \mathrm{mM}$ & {$[42]$} \\
$\mathrm{Ni}-\mathrm{Pt}$ & 66.9 & $0.1-30.1 \mathrm{mM}$ & {$[43]$} \\
$\mathrm{Ni} / \mathrm{Al}$ LDH nanosheet & 24.45 & $5 \mu \mathrm{M}-10 \mathrm{mM}$ & {$[44]$} \\
PVP-GNs-NiNPs-CS & 103.8 & $0.1 \mu \mathrm{M}-0.5 \mathrm{mM}$ & {$[45]$} \\
PtNi-ERGO/GCE & 20.4 & $\mathrm{Up} \mathrm{to} 35 \mathrm{mM}$ & {$[46]$} \\
HollowPt-Ni-graphene & 30.3 & $0.5-20.0 \mathrm{mM}$ & {$[47]$} \\
\hline
\end{tabular}

\subsection{Specificity and Reproducibility of the NiFe/GO/GCE Electrode}

Dopamine (DA), ascorbic acid (AA), and uric acid (UA) coexist in human blood, which influences the electrochemical nonenzymatic glucose sensing. To investigate the effect of DA, AA, and UA on glucose sensing, an amperometric response test was carried out. Figure 9 shows the amperometric response current with the addition of DA, AA, UA, and glucose. It can be seen that the current generated by DA, AA, and UA in normal physiological concentrations are only $4.1 \%, 1.9 \%$, and $2.6 \%$, respectively, compared to that of glucose. This research demonstrates that the NiFe/GO/GCE electrode possesses specificity for glucose sensing and thus can be used in real-world sensing applications. 


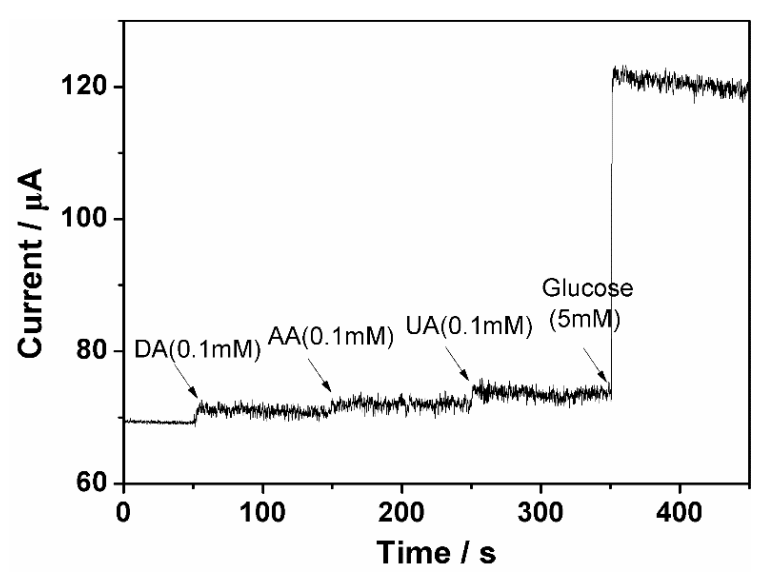

Figure 9. Amperometric response of the NiFe/GO/GCE electrode with interference by dopamine (DA), ascorbic acid (AA), and uric acid (UA) at physiological concentrations.

To check the reproducibility of our manufacturing operation, we fabricated two electrodes in the same conditions and tested their double-layer capacitance (Cdl). Cyclic voltammograms were carried out in $0.1 \mathrm{M} \mathrm{NaOH}$ solution at scan rates from 10 to $100 \mathrm{mV} \mathrm{s}^{-1}$ (Figure 10a,b). Then, the electrochemically active surface area was estimated by testing the capacitive current at non-Faraday regions at different scan rates, from which the double-layer capacitance $(\mathrm{Cdl})$ was determined by plotting the $\triangle \mathrm{J}=\left(\mathrm{J}_{\mathrm{a}}-\mathrm{J}_{\mathrm{c}}\right)$ at $0.10 \mathrm{~V}$ versus $\mathrm{Ag} / \mathrm{AgCl}$ against the scan rate, as shown in Figure 10c. The linear slope is equivalent to double the $\mathrm{Cdl}$, which can be used to represent the electrochemically active surface area [48]. From Figure 10c, it can be seen that the two fabricated electrodes have almost the same linear slope, revealing the same electrochemically active surface area of the two electrodes fabricated in the same conditions. That is, our fabrication process is reliable.
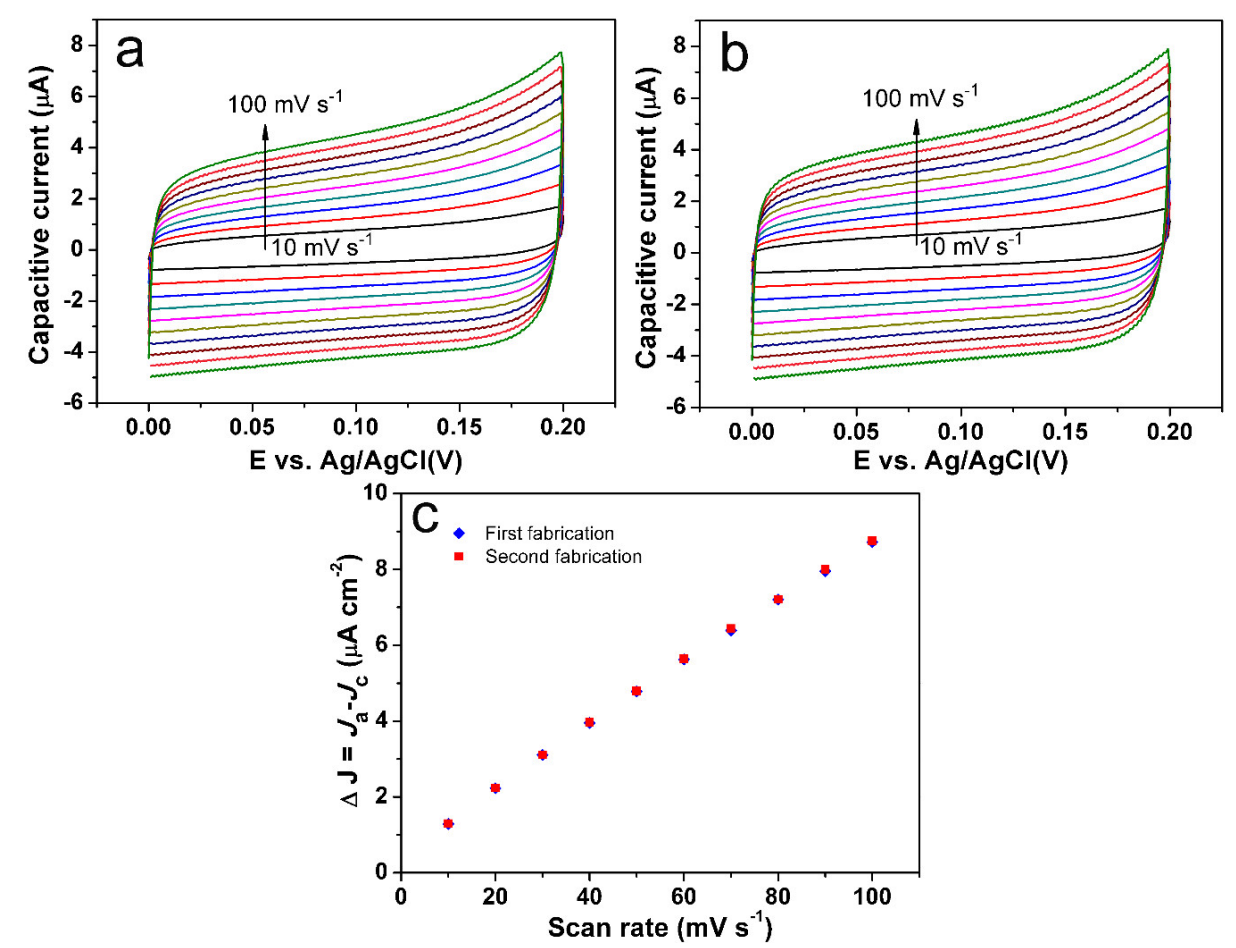

Figure 10. Cyclic voltammograms with different scan rates in the potential range of $0.0 \mathrm{~V}$ to $0.2 \mathrm{~V}$ vs. $\mathrm{Ag} / \mathrm{AgCl}$, where no Faradaic processes occur for the first (a) and second fabrication (b) of the electrode. Charging current density differences for the first and second fabrications (c) of the electrode are plotted against scan rates. 


\subsection{Practical Applications}

For practical analysis, the NiFe/GO/GCE electrode was used to detect the glucose concentration in human serum by amperometric measurement. Briefly, $20 \mu \mathrm{L}$ of serum was injected into $15 \mathrm{~mL}$ of $0.1 \mathrm{M} \mathrm{NaOH}$ solution, and then the current response at $+0.55 \mathrm{~V}$ on NiFe/GO/GCE was recorded. The recovery value was confirmed by standard injection of glucose with a known concentration to the above sample, then recording the current at $+0.55 \mathrm{~V}$. As listed in Table 2, the recovery values of all three samples were close to $100 \%$, indicating good practical application potential of the $\mathrm{NiFe} / \mathrm{GO} / \mathrm{GCE}$ electrode.

Table 2. Amperometric detection of glucose in serum.

\begin{tabular}{cccccc}
\hline Sample & $\begin{array}{c}\text { Concentration } \\
\left(\mathbf{m m o l ~ L}^{-1}\right)\end{array}$ & RSD (\%) & $\begin{array}{c}\text { Added } \\
\left(\mathbf{m m o l ~ L}^{-1}\right)\end{array}$ & $\begin{array}{c}\text { Found } \\
\left(\mathbf{m m o l ~ L}^{-1}\right)\end{array}$ & Recovery (\%) \\
\hline 1 & 9.3 & 3.5 & 1 & 10.1 & 98 \\
2 & 5.8 & 3.1 & 1 & 6.7 & 99 \\
3 & 7.1 & 3.4 & 1 & 8.0 & 99 \\
\hline
\end{tabular}

\section{Conclusions}

In summary, a NiFe/GO/GCE electrochemical glucose sensor has been successfully fabricated. The addition of the Fe element into Ni nanoparticles to form NiFe alloy nanoparticles improved the electrochemical performance of the glucose sensor, which showed higher current than the Ni/GO electrode. In addtion, the GO not only acts as a support to load the NiFe alloy from aggregation, but also plays an important role for electronic transmission. The NiFe/GO/GCE showed best performance when the ratio of $\mathrm{Fe}$ to $\mathrm{Ni}$ was 1:1. It was determined that $60 \mu \mathrm{g}$ is the optimum loading amount in the tested conditions. The NiFe/GO/GCE electrode exhibited excellent sensitivity $\left(173 \mu \mathrm{AmM}^{-1} \mathrm{~cm}^{-2}\right)$ and a wide detection linear range (up to $5 \mathrm{mM}$ ). In addition, the NiFe/GO/GCE electrode shows high selectivity for glucose detection and can be applied to glucose detection in human serum. All results demonstrate that the NiFe/GO/GCE electrode is a promising candidate in the development of cheap, stable, and sensitive nonenzymatic glucose sensors.

Author Contributions: Data curation, Z.D.; Formal analysis, Z.D., Y.S. and J.D.; Investigation, Z.D., Y.S. and J.D.; Resources, Y.W.; Writing-Original Draft Preparation, Y.W. and Z.D.; Writing-review and editing, Z.D., Y.S. and Y.W.; Project Administration, Y.W.; Funding acquisition, J.D. All the authors discussed the results and commented on the manuscript.

Funding: This research was funded by the National Natural Science Foundation of China, grant number 21263023; Natural Science Foundation of Gansu Province, grant number 1606RJZA209; Central Universities Fundamental Research Foundation, grant number 31920160055; and the Youth Science Foundation of Gansu Province, grant number 17JR5RA282. The APC was funded by the Natural Science Foundation of Gansu Province, grant number 17JR5RA172.

Acknowledgments: The authors thank all the reviewers and editors for their great help and useful suggestions, and thank Jingwei Huang and MDPI English Editing Service for their help in English editing.

Conflicts of Interest: The authors declare no conflict of interest.

\section{References}

1. Scognamiglio, V. Nanotechnology in glucose monitoring: Advances and challenges in the last 10 years. Biosens. Bioelectron. 2013, 47C, 12-25. [CrossRef] [PubMed]

2. Clark, L.C.; Lyons, C. Electrode systems for continuous monitoring in cardiovascular surgery. Ann. Ny. Acad. Sci. 1962, 102, 29-45. [CrossRef] [PubMed]

3. Niu, X.H.; Shi, L.B.; Zhao, H.L.; Lan, M.B. Advanced strategies for improving the analytical performance of Pt-based nonenzymatic electrochemical glucose sensors: A minireview. Anal. Methods 2016, 8, 1755-1764. [CrossRef] 
4. Gnana kumar, G.; Amala, G.; Gowtham, S.M. Recent advancements, key challenges and solutions in non-enzymatic electrochemical glucose sensors based on graphene platforms. RSC Adv. 2017, 7, 36949-36976. [CrossRef]

5. Xie, J.D.; Gu, S.; Zhang, H. Microwave deposition of palladium catalysts on graphite spheres and reduced graphene oxide sheets for electrochemical glucose Sensing. Sensors 2017, 17, 2163. [CrossRef]

6. Yang, M.H.; Yang, Y.H.; Liu, Y.L.; Shen, G.L.; Yu, R.Q. Platinum nanoparticles-doped sol-gel/carbon nanotubes composite electrochemical sensors and biosensors. Biosens. Bioelectron. 2006, 21, 1125-1131. [CrossRef] [PubMed]

7. Niu, X.; Li, X.; Pan, J.; He, Y.; Qiu, F.; Yan, Y. Recent advances in non-enzymatic electrochemical glucose sensors based on non-precious transition metal materials: Opportunities and challenges. RSC Adv. 2016, 6, 84893-84905. [CrossRef]

8. Ma, L.; Wang, X.; Zhang, Q.; Tong, X.; Zhang, Y.; Li, Z. Pt catalyzed formation of a Ni@Pt/reduced graphene oxide nanocomposite: Preparation and electrochemical sensing application for glucose detection. Anal. Methods 2018, 10, 3845-3850. [CrossRef]

9. Jin, L.; Meng, Z.; Zhang, Y.; Cai, S.; Zhang, Z.; Li, C.; Shang, L.; Shen, Y. Ultrasmall Pt nanoclusters as robust peroxidase mimics for colorimetric detection of glucose in human serum. ACS Appl. Mater. Interfaces 2017, 9, 10027-10033. [CrossRef] [PubMed]

10. Jiang, L.; Xue, Q.; Jiao, C.; Liu, H.; Zhou, Y.; Ma, H.; Yang, Q. A non-enzymatic nanoceria electrode for non-invasive glucose monitoring. Anal. Methods 2018, 10, 2151-2159. [CrossRef]

11. Zhao, W.; Zhang, R.; Xu, S.; Cai, J.; Zhu, X.; Zhu, Y.; Wei, W.; Liu, X.; Luo, J. Molecularly imprinted polymeric nanoparticles decorated with Au NPs for highly sensitive and selective glucose detection. Biosens. Bioelectron. 2018, 100, 497-503. [CrossRef] [PubMed]

12. Xiao, X.Y.; Montano, G.A.; Edwards, T.L.; Washburn, C.M.; Brozik, S.M.; Wheeler, D.R.; Burckel, D.B.; Polsky, R. Lithographically defined 3D nanoporous nonenzymatic glucose sensors. Biosens. Bioelectron. 2011, 26, 3641-3646. [CrossRef] [PubMed]

13. Wang, Q.; Wang, Q.; Qi, K.; Xue, T.; Liu, C.; Zheng, W.; Cui, X. In situ preparation of porous Pd nanotubes on a GCE for non-enzymatic electrochemical glucose sensors. Anal. Methods 2015, 7, 8605-8610. [CrossRef]

14. Wang, J. Electrochemical glucose biosensors. Chem. Rev. 2008, 108, 814-825. [CrossRef] [PubMed]

15. Huang, J.; He, Y.; Jin, J.; Li, Y.; Dong, Z.; Li, R. A novel glucose sensor based on MoS2 nanosheet functionalized with Ni nanoparticles. Electrochim. Acta 2014, 136, 41-46. [CrossRef]

16. Shu, Y.; Yan, Y.; Chen, J.; Xu, Q.; Pang, H.; Hu, X. Ni and NiO nanoparticles decorated metal-organic framework nanosheets: Facile synthesis and high-performance nonenzymatic glucose detection in human serum. ACS Appl. Mater. Interfaces 2017, 9, 22342-22349. [CrossRef] [PubMed]

17. Mao, Y.; Tian, S.; Gong, S.; Qin, Y.; Han, J.; Deng, S. A broad-spectrum sweet taste sensor based on $\mathrm{Ni}(\mathrm{OH}) 2 / \mathrm{Ni}$ electrode. Sensors 2018, 18, 2758. [CrossRef] [PubMed]

18. Huang, M.; Luo, X.; He, D.; Jiang, P. Hierarchical $\mathrm{Co}(\mathrm{OH}) 2$ nanotube arrays grown on carbon cloth for use in non-enzymatic glucose sensing. Anal. Methods 2017, 9, 5903-5909. [CrossRef]

19. Huang, J.; Dong, Z.; Li, Y.; Li, J.; Wang, J.; Yang, H.; Li, S.; Guo, S.; Jin, J.; Li, R. High performance non-enzymatic glucose biosensor based on copper nanowires-carbon nanotubes hybrid for intracellular glucose study. Sens. Actuator B Chem. 2013, 182, 618-624. [CrossRef]

20. Ma, J.; Wang, J.; Wang, M.; Zhang, G.; Peng, W.; Li, Y.; Fan, X.; Zhang, F. Preparation of cuprous oxide mesoporous spheres with different pore sizes for non-enzymatic glucose detection. Nanomaterials 2018, 8, 73. [CrossRef] [PubMed]

21. Huang, J.; Hu, G.; Ding, Y.; Pang, M.; Ma, B. Mn-doping and NiFe layered double hydroxide coating: Effective approaches to enhancing the performance of $\alpha-\mathrm{Fe} 2 \mathrm{O} 3$ in photoelectrochemical water oxidation. J. Catal. 2016, 340, 261-269. [CrossRef]

22. Yeh, T.H.; Liu, C.W.; Chen, H.S.; Wang, K.W. Preparation of carbon-supported PtM (M = Au, Pd, or Cu) nanorods and their application in oxygen reduction reaction. Electrochem. Commun. 2013, 31, 125-128. [CrossRef]

23. Sun, Y.; Yang, H.; Yu, X.; Meng, H.; Xu, X. A novel non-enzymatic amperometric glucose sensor based on a hollow Pt-Ni alloy nanotube array electrode with enhanced sensitivity. RSC Adv. 2015, 5, 70387-70394. [CrossRef] 
24. Chen, C.C.; Chen, L.C. Synthesis and characterization of Pd-Ni core-shell nanocatalysts for alkaline glucose electrooxidation. RSC Adv. 2015, 5, 53333-53339. [CrossRef]

25. Yang, J.; Liang, X.; Cui, L.; Liu, H.; Xie, J.; Liu, W. A novel non-enzymatic glucose sensor based on Pt3Ru1 alloy nanoparticles with high density of surface defects. Biosens. Bioelectron. 2016, 80, 171-174. [CrossRef] [PubMed]

26. He, W.; Sun, Y.; Xi, J.; Abdurhman, A.A.M.; Ren, J.; Duan, H. Printing graphene-carbon nanotube-ionic liquid gel on graphene paper: Towards flexible electrodes with efficient loading of PtAu alloy nanoparticles for electrochemical sensing of blood glucose. Anal. Chim. Acta 2016, 903, 61-68. [CrossRef] [PubMed]

27. Zhao, A.; Zhang, Z.; Zhang, P.; Xiao, S.; Wang, L.; Dong, Y.; Yuan, H.; Li, P.; Sun, Y.; Jiang, X.; et al. 3D nanoporous gold scaffold supported on graphene paper: Freestanding and flexible electrode with high loading of ultrafine PtCo alloy nanoparticles for electrochemical glucose sensing. Anal. Chim. Acta 2016, 938, 63-71. [CrossRef] [PubMed]

28. Suneesh, P.V.; Sara Vargis, V.; Ramachandran, T.; Nair, B.G.; Satheesh Babu, T.G. Co-Cu alloy nanoparticles decorated $\mathrm{TiO}_{2}$ nanotube arrays for highly sensitive and selective nonenzymatic sensing of glucose. Sens. Actuator B Chem. 2015, 215, 337-344. [CrossRef]

29. Sheng, Q.; Liu, D.; Zheng, J. NiCo alloy nanoparticles anchored on polypyrrole/reduced graphene oxide nanocomposites for nonenzymatic glucose sensing. New J. Chem. 2016, 40, 6658-6665. [CrossRef]

30. Han, B.; Pan, M.; Zhou, J.; Wang, Y.; Wang, Z.; Jiao, J.; Zhang, C.; Chen, Q. Facile synthesis of $\beta$-Lactoglobulin-Functionalized reduced graphene oxide and trimetallic PtAuPd nanocomposite for electrochemical sensing. Nanomaterials 2018, 8, 724. [CrossRef] [PubMed]

31. Jiang, L.C.; Zhang, W.D. A highly sensitive nonenzymatic glucose sensor based on CuO nanoparticlesmodified carbon nanotube electrode. Biosens. Bioelectron. 2010, 25, 1402-1407. [CrossRef] [PubMed]

32. Wu, H.X.; Cao, W.M.; Li, Y.; Liu, G.; Wen, Y.; Yang, H.F.; Yang, S.P. In situ growth of copper nanoparticles on multiwalled carbon nanotubes and their application as non-enzymatic glucose sensor materials. Electrochim. Acta 2010, 55, 3734-3740. [CrossRef]

33. Novoselov, K.S.; Geim, A.K.; Morozov, S.V.; Jiang, D.; Zhang, Y.; Dubonos, S.V.; Grigorieva, I.V.; Firsov, A.A. Electric field effect in atomically thin carbon films. Science 2004, 306, 666-669. [CrossRef] [PubMed]

34. Radhakrishnan, S.; Kim, S.J. Facile fabrication of NiS and a reduced graphene oxide hybrid film for nonenzymatic detection of glucose. RSC Adv. 2015, 5, 44346-44352. [CrossRef]

35. Yan, X.; Gu, Y.; Li, C.; Zheng, B.; Li, Y.; Zhang, T.; Zhang, Z.; Yang, M. A non-enzymatic glucose sensor based on the CuS nanoflakes-reduced graphene oxide nanocomposite. Anal. Methods 2018, 10, 381-388. [CrossRef]

36. Yu, X.; Yang, P.; Chen, S.; Zhang, M.; Shi, G. NiFe alloy protected silicon photoanode for efficient water splitting. Adv. Energy Mater. 2017, 7, 1601805. [CrossRef]

37. Bin, D.; Yang, B.; Li, C.; Liu, Y.; Zhang, X.; Wang, Y.; Xia, Y. In situ growth of NiFe alloy nanoparticles embedded into $\mathrm{N}$-doped bamboo-like carbon nanotubes as a bifunctional electrocatalyst for $\mathrm{Zn}$ Air batteries. ACS Appl. Mater. Interfaces 2018, 10, 26178-26187. [CrossRef] [PubMed]

38. Wang, G.; Zheng, D.; Liu, D.; Harris, J.; Si, J.; Ding, T.; Qu, D. Highly efficient Ni Fe based oxygen evolution catalyst prepared by a novel pulse electrochemical approach. Electrochim. Acta 2017, 247, 722-729. [CrossRef]

39. Torabinejad, V.; Aliofkhazraei, M.; Assareh, S.; Allahyarzadeh, M.H.; Rouhaghdam, A.S. Electrodeposition of Ni-Fe alloys, composites, and nano coatings-A review. J. Alloy. Compd. 2017, 691, 841-859. [CrossRef]

40. Hummers, W.S., Jr.; Offeman, R.E. Preparation of graphitic oxide. J. Am. Chem. Soc. 1958, 80, 1339. [CrossRef]

41. Li, J.; Tang, W.; Huang, J.; Jin, J.; Ma, J. Polyethyleneimine decorated graphene oxide-supported Ni1-xFex bimetallic nanoparticles as efficient and robust electrocatalysts for hydrazine fuel cells. Catal. Sci. Technol. 2013, 3, 3155-3162. [CrossRef]

42. Hui, S.; Zhang, J.; Chen, X.; Xu, H.; Ma, D.; Liu, Y.; Tao, B. Study of an amperometric glucose sensor based on Pd-Ni/SiNW electrode. Sens. Actuator B Chem. 2011, 155, 592-597. [CrossRef]

43. Mei, H.; Wu, W.; Yu, B.; Wu, H.; Wang, S.; Zhang, X.; Xia, Q. Electrochemical sensor for detection of glucose based on Ni@Pt core-shell nanoparticles supported on carbon. Electroanalysis 2016, 28, 671-678. [CrossRef]

44. Li, X.; Liu, J.; Ji, X.; Jiang, J.; Ding, R.; Hu, Y.; Hu, A.; Huang, X. Ni/ Al layered double hydroxide nanosheet film grown directly on Ti substrate and its application for a nonenzymatic glucose sensor. Sens. Actuator B Chem. 2010, 147, 241-247. [CrossRef] 
45. Liu, Z.; Guo, Y.; Dong, C. A high performance nonenzymatic electrochemical glucose sensor based on polyvinylpyrrolidone-graphene nanosheets-nickel nanoparticles-chitosan nanocomposite. Talanta 2015, 137, 87-93. [CrossRef] [PubMed]

46. Gao, H.; Xiao, F.; Ching, C.B.; Duan, H. One-step electrochemical synthesis of PtNi nanoparticle-graphene nanocomposites for nonenzymatic amperometric glucose detection. ACS Appl. Mater. Interfaces 2011, 3, 3049-3057. [CrossRef] [PubMed]

47. Hu, Y.; He, F.; Ben, A.; Chen, C. Synthesis of hollow Pt-Ni-graphene nanostructures for nonenzymatic glucose detection. J. Electroanal. Chem. 2014, 726, 55-61. [CrossRef]

48. Song, F.; Hu, X. Ultrathin cobalt manganese layered souble hydroxide is an efficient oxygen evolution catalyst. J. Am. Chem. Soc. 2014, 136, 16481-16484. [CrossRef] [PubMed]

(C) 2018 by the authors. Licensee MDPI, Basel, Switzerland. This article is an open access article distributed under the terms and conditions of the Creative Commons Attribution (CC BY) license (http://creativecommons.org/licenses/by/4.0/). 